\title{
Changes in Carbohydrate Metabolism in Plasmopara viticola-Infected Grapevine Leaves
}

\author{
Magdalena Gamm, ${ }^{1}$ Marie-Claire Héloir, ${ }^{1}$ Richard Bligny, ${ }^{2}$ Nathalie Vaillant-Gaveau, ${ }^{3}$ Sophie Trouvelot, ${ }^{4}$ \\ Gérard Alcaraz, ${ }^{5}$ Patrick Frettinger, ${ }^{1}$ Christophe Clément, ${ }^{3}$ Alain Pugin, ${ }^{1}$ David Wendehenne, ${ }^{1}$ and \\ Marielle Adrian ${ }^{4}$ \\ 1UMR INRA1088 / CNRS 5184 / Université de Bourgogne Plante Microbe Environnement, 17 rue Sully, BP 86510, 21065 \\ Dijon cedex, France; ${ }^{2}$ Laboratoire de Physiologie cellulaire végétale, CEA Grenoble, 17 rue des Martyrs, 38054 Grenoble \\ cedex 9, France; ${ }^{3}$ Laboratoire de Stress, Défenses et Reproduction des Plantes, URVVC-UPRES EA 2069, Bâtiment 18, \\ Moulin de la Housse, BP 1039, 51687 Reims Cedex 2, France; ${ }^{4}$ IUVV-Université de Bourgogne-UMR INRA 1088/CNRS \\ 5184/Université de Bourgogne Plante Microbe Environnement, 17 rue Sully, BP 86510, 21065 Dijon Cedex, France ${ }^{5}$ UPSP \\ Proxiss-AGROSUP DIJON, 26 Bd Dr Petitjean, BP 87999, 21079 Dijon Cedex, France
}

Submitted 21 February 2011. Accepted 12 May 2011.

The oomycete Plasmopara viticola is responsible for downy mildew, a severe grapevine disease. In infected grapevine leaves, we have observed an abnormal starch accumulation at the end of the dark period, suggesting modifications in starch metabolism. Therefore, several complementary approaches, including transcriptomic analyses, measurements of enzyme activities, and sugar quantification, were performed in order to investigate and to understand the effects of $P$. viticola infection on leaf starch and-to a larger extent-carbohydrate metabolism. Our results indicate that starch accumulation is associated with an increase in ADP-glucose pyrophosphorylase (AGPase) activity and modifications in the starch degradation pathway, especially an increased $\alpha$ amylase activity. Together with these alterations in starch metabolism, we have observed an accumulation of hexoses, an increase in invertase activity, and a reduction of photosynthesis, indicating a source-to-sink transition in infected leaf tissue. Additionally, we have measured an accumulation of the disaccharide trehalose correlated to an increased trehalase gene expression and enzyme activity. Altogether, these results highlight a dramatic alteration of carbohydrate metabolism correlated with later stages of $P$. viticola development in leaves.

Plasmopara viticola is the causal agent for grapevine downy mildew, a severe disease which affects harvest quality and quantity. This disease remains problematic because its control requires frequent fungicide applications in wet weather. $P$. viticola is an obligate biotrophic oomycete which needs living tissue for nutrient uptake, growth, and reproduction. It uses stomata to penetrate into leaves, develops an intercellular mycelium with haustoria for nutrient uptake from mesophyll cells, and subsequently reaches other stomata for sporulation. The disease is characterized by the occurrence of typical "oil-spot symptoms" on the upper side of the leaf. In infected leaves, we

Corresponding author: M. Adrian; Telephone: +33 (0)3 806937 21; Fax: +33 (0)3 806932 26; E-mail: marielle.adrian@u-bourgogne.fr

* The $\boldsymbol{e}$-Xtra logo stands for "electronic extra" and indicates that three supplementary tables and two supplementary figures are published online. have observed an abnormal starch accumulation at the end of the dark period, suggesting modifications in the carbohydrate metabolism.

Recently, the effects of pathogen infection on plant primary metabolism have aroused new interest (Berger et al. 2007). Plants need photoassimilates to fuel the activation of defense reactions and to mediate physiological adaptations (Bolton 2009) whereas pathogens attempt to manipulate the plant to use carbohydrates for their development. Both compete for sugars, resulting in modifications of photoassimilate production and partitioning within host tissues (Abood and Lösel 2003; Hall and Williams 2000; Scholes et al. 1994).

Plants produce carbohydrates in photosynthetic source organs and export them toward sugar-importing sink organs. During the day, a part of the sugars is retained in leaf chloroplasts and metabolized in transitory starch, which is degraded during the dark period to support leaf metabolism and sucrose export. Starch, the major form of plant carbon storage, is mainly composed of branched amylopectin and also the nonbranched amylose. Both molecules are polymers of $\alpha-1,4-$ and $\alpha-1,6-$ linked glucose units. Starch synthesis involves ADP-glucose pyrophosphorylase (AGPase) (EC 2.7.7.27), starch synthases (EC 2.4.1.21), and branching enzymes (EC 2.4.1.25 3.2.1.33) (Zeeman et al. 2007). The knowledge of starch breakdown mechanisms in plastids remains incomplete. It is proposed that phosphorylation by glucan, water dikinase (EC 2.7.9.4), and phosphoglucan water dikinase (PWD) (EC 2.7.9.4) is required to allow the subsequent degradation by $\beta$-amylases (EC 3.2.1.2) (Lloyd et al. 2005; Scheidig et al. 2002; Smith et al. 2005). The role of $\alpha$-amylases (EC 3.2.1.1) in leaf starch degradation remains uncertain (Llyod et al. 2005).

Plant sugar concentrations alter in response to diurnal changes and biotic and abiotic stresses (Rolland et al. 2006). In addition to their role as resources for respiration, metabolic intermediates, and storage components, sugars are signaling molecules and can impact gene expression and enzyme activity, especially those related to carbohydrate metabolism and photosynthesis (Koch 2004; Rolland et al. 2002; Smeekens 2000). For example, glucose or sucrose repress the expression of genes encoding the small subunit of ribulose bisphosphate carboxylase (EC 4.1.1.39, Rubisco), the chlorophyll a/b binding protein, and $\alpha$-amylase (Gibson 2005; Krapp et al. 1993), whereas both induce the expression of the gene encoding ex- 
tracellular invertase (EC 3.2.1.26) (Roitsch 1999; Sheen et al. 1999). In Arabidopsis, trehalose activates the transcription of AGPase genes (Wingler et al. 2000). Sugars also regulate enzyme activities. For example, extracellular invertase activity is induced by glucose and sucrose in Chenopodium rubrum (Roitsch et al. 1995) and by sucrose in tomato (Godt and Roitsch 1997; Sinha et al. 2002).

Invertases are key enzymes for carbohydrate allocation because they catalyze the irreversible cleavage of sucrose, the major form of translocated sugars in plants, into glucose and fructose. Plants contain several isoforms of invertases that differ by their subcellular localization, $\mathrm{pH}$ optimum, and isoelectric point (Godt and Roitsch 1997). Soluble intracellular invertases (vacuolar acidic and cytoplasmic alkaline) can be distinguished from acidic apoplastic or cell-wall invertases. The cell-wall invertase activity is an important determinant of local sink strength (Sturm 1999). Invertases are not plant specific and are also present in bacteria and fungi such as Aspergillus spp. or Uromyces fabae (Voegele et al. 2006). An increase in invertase activity is a common feature of plant-pathogen interactions (Fotopoulos et al. 2003; Roitsch et al. 2003; Sutton et al. 2007; Voegele et al. 2006). In compatible plant-biotrophic microorganism interactions, it is associated with a reduction in the rate of net photosynthesis (Chou et al. 2000; Tang et al. 1996) and an accumulation of hexose sugars at the site of infection, resulting in a local shift of source to sink (Scholes et al. 1994). In grapevine leaves infected by powdery and downy mildew, Brem and associates (1986) have described an increase of acid invertase activity and, more recently, Hayes and associates (2010) have reported changes in the expression of apoplastic invertase and hexose transporter genes.

Whereas grapevine- $P$. viticola interaction has already been described in a context of genetic or induced resistance (Dai 1995; Díez-Navajas et al. 2008, Trouvelot et al. 2008), to our knowledge, neither a deregulation of starch metabolism nor a general view of the effect of the infection on carbohydrate metabolism was reported until now. Therefore, in this study, several complementary approaches, including transcriptomic analyses, measurements of enzyme activities, and sugar quantification, were used in order to understand the mechanisms responsible for starch abnormal accumulation and to investigate the effect of $P$. viticola infection on the leaf carbohydrate metabolism.

\section{RESULTS}

\section{$P$. viticola development induces abnormal starch accumulation.}

$P$. viticola development was monitored by analysis of the ratio of pathogen/leaf DNA content (coefficient of infection) and visualized by microscopy after aniline blue staining (Fig. 1). At 1 day postinoculation (dpi), zoospores have reached stomata, encysted, and initiated germination. The oomycete DNA was detectable from $3 \mathrm{dpi}$, when hyphae have developed and
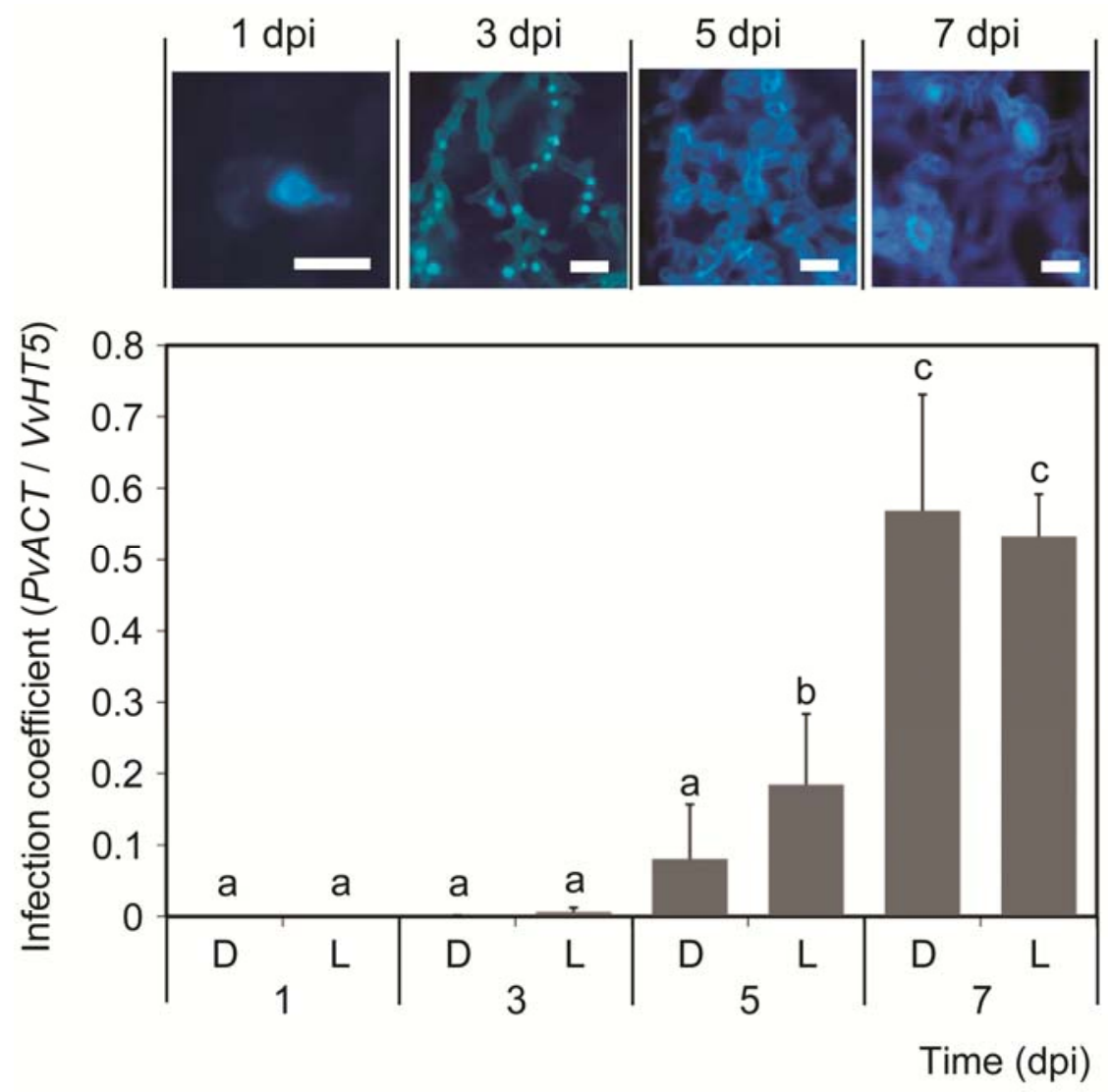

Fig. 1. Monitoring of Plasmopara viticola development in Vitis vinifera 'Marselan' leaves by UV epifluorescence after aniline blue staining and DNA quantification at different times postinoculation. Images present the different stages of development. Infection coefficient representing the ratio between pathogen DNA $(P v A C T)$ and host DNA (VvHT5) quantified by real-time polymerase chain reaction. Leaf samples were collected during the light period (L) and at the end of the dark period (D) over a time course of infection (1 to 7 days postinoculation [dpi]). At 1 dpi, zoospores have reached stomata, encysted, and initiated germination. At $3 \mathrm{dpi}$, developing hyphae have formed haustoria in contact with the host mesophyll cells. At 5 dpi, the pathogen has highly colonized the host tissues and, at $7 \mathrm{dpi}$, it is present in the substomatal cavities to prepare sporulation. Scale bars correspond to $10 \mu \mathrm{m}$. Images are representative of three biological replicates. Data correspond to the average of four independent biological replicates \pm standard deviation. Means with different letters (a, b, c) are significantly different $(P<0.05)$. 
formed haustoria in mesophyll cells. The coefficient of infection increased significantly from $5 \mathrm{dpi}$ concomitantly to extensive leaf colonization and to the occurrence of the "oil-spot" symptoms. It reached a maximum when symptoms were spread over most of the leaf surface and the oomycete was ready to initiate sporangiophores (7 dpi).

Lugol staining was used to visualize starch in control and $P$. viticola-infected leaves when the coefficient of infection reached the maximum ( $7 \mathrm{dpi}$ ). At the end of the dark period, control leaves showed no starch (Fig. 2A) whereas, in infected leaves, starch was co-localized with the oil-spot symptoms (Fig. 2B). During the light period, starch was evenly distributed in control leaves whereas it seemed preferentially localized in oil spots of infected leaves (data not shown).

Ultrathin cuts of control and inoculated (6 dpi) leaves, collected at the end of the dark period, were observed using transmission electron microscopy. In the spongy parenchyma cells of control leaves, some chloroplasts seemed to contain only small starch amounts, as indicated by the presence of few and relatively small granules (Fig. 2C). In infected leaves, however, chloroplasts contained voluminous starch granules but the integrity of such chloroplasts seemed unaltered (Fig. 2D).

The starch content was determined in leaf extracts by the measure of glucose units released after enzymatic digestion. For leaf extracts sampled during the light period, glucose at approximately $13 \mathrm{mg} / \mathrm{g}$ fresh weight $(\mathrm{FW})$ was detected and no significant differences between control and $P$. viticola-inoculated plants were observed (ratio of approximately 1) (Fig. 3 ). For samples collected at the end of the dark period, glucose at approximately $0.8 \mathrm{mg} / \mathrm{g} \mathrm{FW}$ was measured in control plants. It was not significantly different from the values obtained in infected plants at 1 to $5 \mathrm{dpi}$. At $7 \mathrm{dpi}$, however, the release of glucose was more than sixfold higher in extracts of infected leaves, indicating a higher starch concentration (Fig. 3).

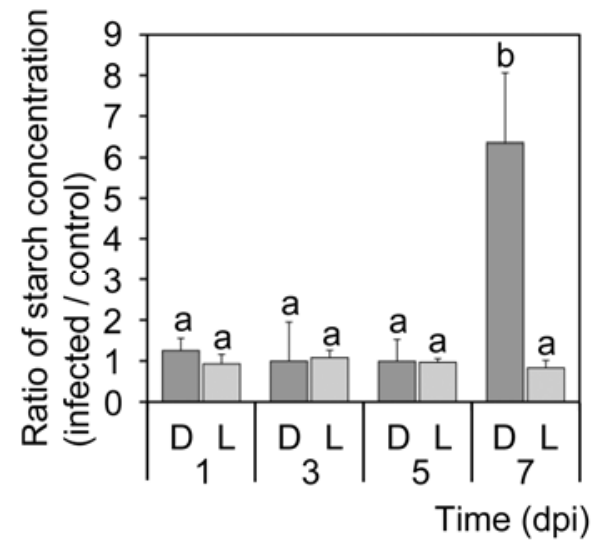

Fig. 3. Ratio of the starch content of Plasmopara viticola-infected versus control grapevine leaves over a time course of infection (1 to 7 days postinoculation [dpi]) in samples collected at the end of the dark period (D) or during the light period (L). Values correspond to the measurement of glucose released after enzymatic degradation of starch. Data correspond to the average of three independent biological replicates \pm standard deviation. Means with different letters $(\mathrm{a}, \mathrm{b})$ are significantly different $(P<$ $0.05)$.
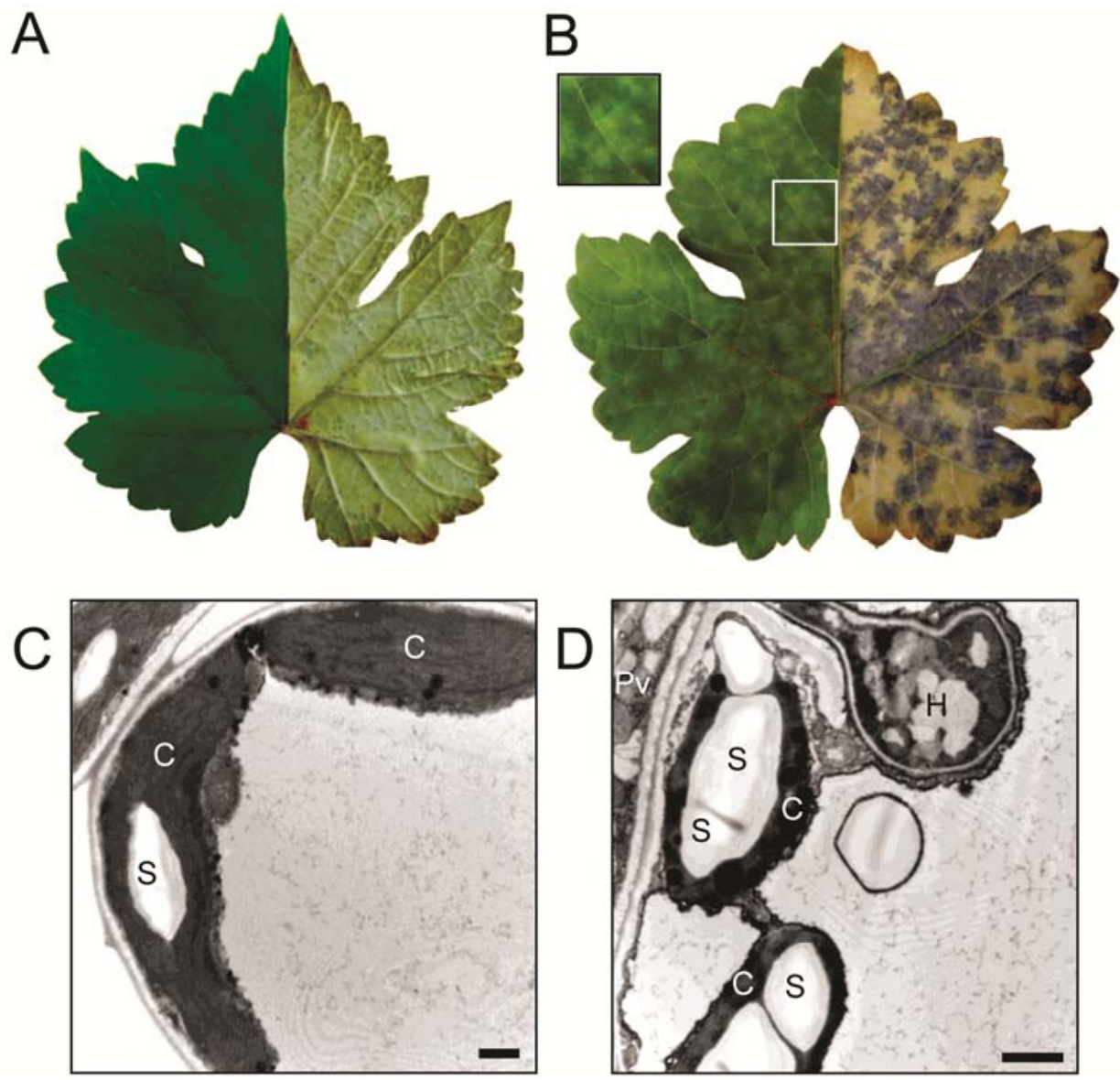

Fig. 2. Starch visualization in control and Plasmopara viticola-infected grapevine leaves at the end of the dark period. A and $\mathbf{B}$, Left part of each image corresponds to a photograph of $\mathbf{A}$, control and $\mathbf{B}, P$. viticola-infected leaves at 7 days postinoculation (dpi). Right part corresponds to the same leaves after clarification and lugol staining. The inset image shows a detail of "oil-spot" symptoms. C and D, Transmission electron micrographs of spongy parenchyma cells of $\mathbf{C}$, control and D, infected leaves at $7 \mathrm{dpi}$. H: haustorium, Pv: P. viticola hyphae, C: chloroplast, S: starch granule. Scale bar corresponds to $1 \mu \mathrm{m}$. 
Modifications of carbohydrate metabolism- and photosynthesis-related gene expression revealed by microarray profiles.

A microarray analysis of control and $P$. viticola-infected grapevine leaves ( $7 \mathrm{dpi}$, end of the dark period) revealed that 3,100 of the nearly 30,000 genes studied were affected by infection. Among the regulated genes, $5.4 \%$ were annotated as related to carbohydrate metabolism, including genes involved in starch and soluble sugar metabolism, and $0.6 \%$ was connected to photosynthesis (Supplementary Fig. S1, Supplementary Table S1). Gene expression of AGPase, soluble starch synthase, PWD, $\beta$-amylase, sucrose phosphate synthase, trehalose phosphate synthase (TPS), Rubisco large subunit, chlorophyll synthase, and chlorophyll a/b binding proteins were repressed,

Table 1. Transcriptional changes for genes involved in carbohydrate metabolism and photosynthesis associated to Plasmopara viticola infection

\begin{tabular}{|c|c|c|c|}
\hline NCBI reference sequence & Annotation & Ratio of gene expression & $P$ value \\
\hline XM_002277244.1 & PSI type II chlorophyll a/b-binding protein & 0.20 & 0.045 \\
\hline XM_002285596.1 & $\alpha, \alpha$-Trehalose-phosphate synthase & 0.23 & 0.015 \\
\hline XM_002271362.1 & Sucrose-phosphate synthase & 0.25 & 0.017 \\
\hline AM424156.2 & Phosphoglucan, water dikinase & 0.25 & 0.050 \\
\hline XM_002267433.1 & Ribulose-1,5 bisphosphate carboxylase/oxygenase large subunit, chloroplastic & 0.31 & 0.027 \\
\hline XM_002281033.1 & Glucose-1-phosphate adenylyltransferase (large subunit 1) (AGPase) & 0.32 & 0.032 \\
\hline XM_002277336.1 & Soluble starch synthase & 0.32 & 0.032 \\
\hline XM_002263235.1 & Chlorophyll synthase, chloroplastic & 0.46 & 0.027 \\
\hline XM_002265662.1 & $\beta$-Amylase & 0.47 & 0.027 \\
\hline XM_002263662.1 & Trehalase & 2.89 & 0.019 \\
\hline XM_002279752.1 & $\beta$-Bructofuranosidase (invertase) & 3.02 & 0.039 \\
\hline XM_002271938.1 & Chlorophyllase-1 & 9.98 & 0.009 \\
\hline XM_002282148.1 & $\alpha$-Amylase & 13.53 & 0.044 \\
\hline
\end{tabular}

${ }^{\mathrm{a}} \mathrm{NCBI}=$ National Center for Biotechnology Information.
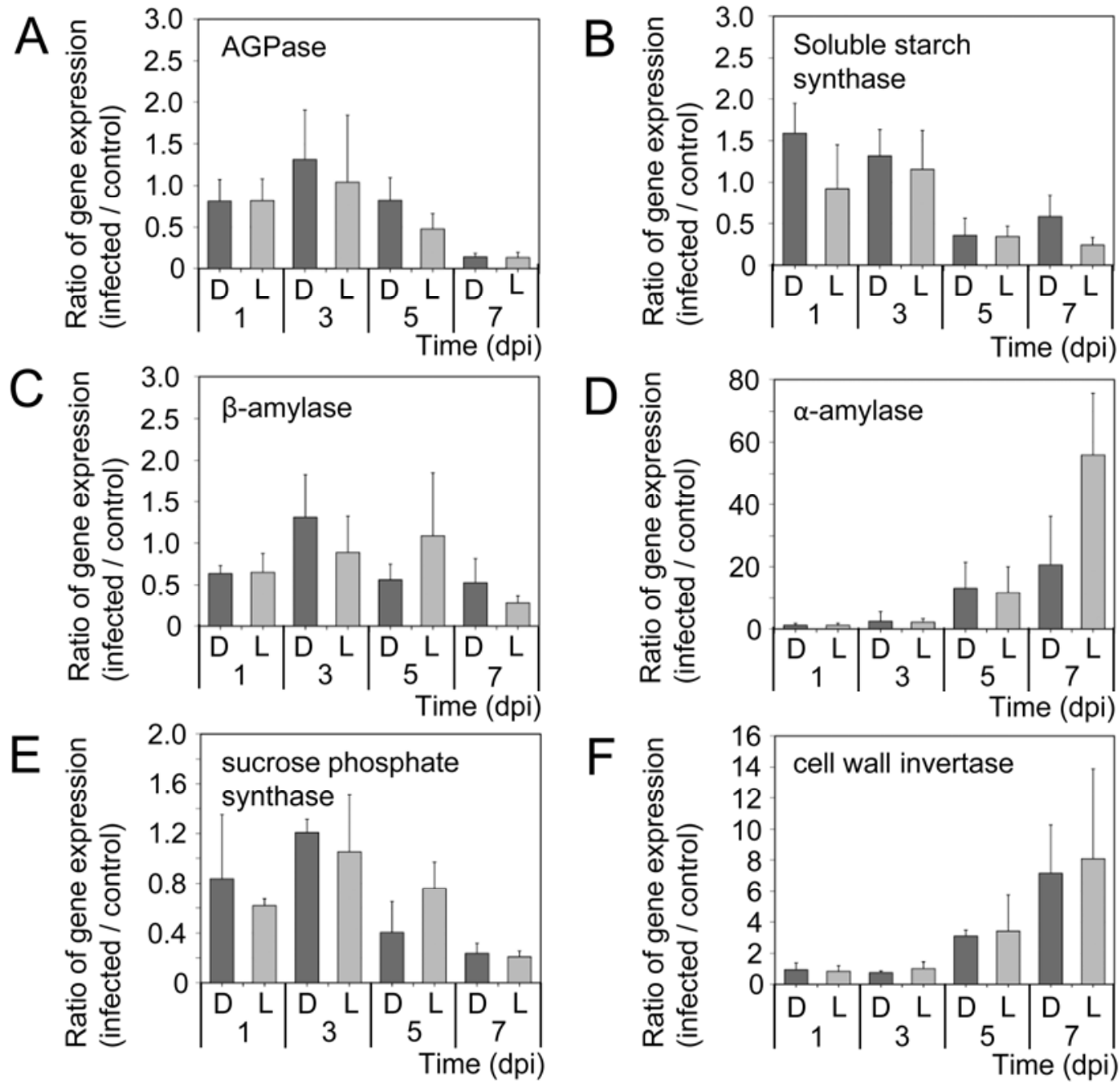

Fig. 4. Relative expression of genes encoding A, ADP-glucose pyrophosphorylase (AGPase); B, soluble starch synthase; $\mathbf{C}, \beta$-amylase; $\mathbf{D}, \alpha$-amylase; $\mathbf{E}$, sucrose phosphate synthase; and $\mathbf{F}$, cell wall invertase analyzed by quantitative reverse-transcription polymerase chain reaction. Leaf samples were collected during the light period (L) and at the end of the dark period (D) during a time course of grapevine leaf infection by Plasmopara viticola (1 to 7 days postinoculation [dpi]). Expression levels obtained for infected leaves were normalized with respect to VATP16 and 60SRP expression and related to the corresponding values of control leaves. Data correspond to the average of three independent biological replicates \pm standard deviation. 
while genes encoding $\alpha$-amylase, invertase, trehalase, and chlorophyllase showed induced expression (Table 1).

\section{Alteration of starch metabolism.}

Quantitative reverse-transcription polymerase chain reaction (qRT-PCR) analysis was performed to validate the variations observed in the microarray profile for a set of genes encoding key enzymes of starch metabolism and to analyze these variations throughout the infection time course. Genes encoding AGPase and soluble starch synthase were both repressed at the end of the infection. The AGPase gene expression was repressed at 7 dpi during both the dark and light periods (Fig. 4A), whereas that of soluble starch synthase was repressed from 5 dpi (Fig. 4B). Whereas the $\beta$-amylase gene expression varied slightly over the course of infection and was repressed at 7 dpi during the light period (Fig. 4C), that of $\alpha$-amylase was clearly induced from $5 \mathrm{dpi}$, with a maximal activation at 7 dpi at light (Fig. 4D).

AGPase and $\beta$ - and $\alpha$-amylase activities were measured in control and infected leaves (7 dpi). The AGPase activity was more than sixfold higher in infected than in control leaves for both sampling periods (Fig. 5A). In control plants, the $\beta$-amylase activity was more than three times higher in the dark than during the light period. In infected plants, this activity was simi-
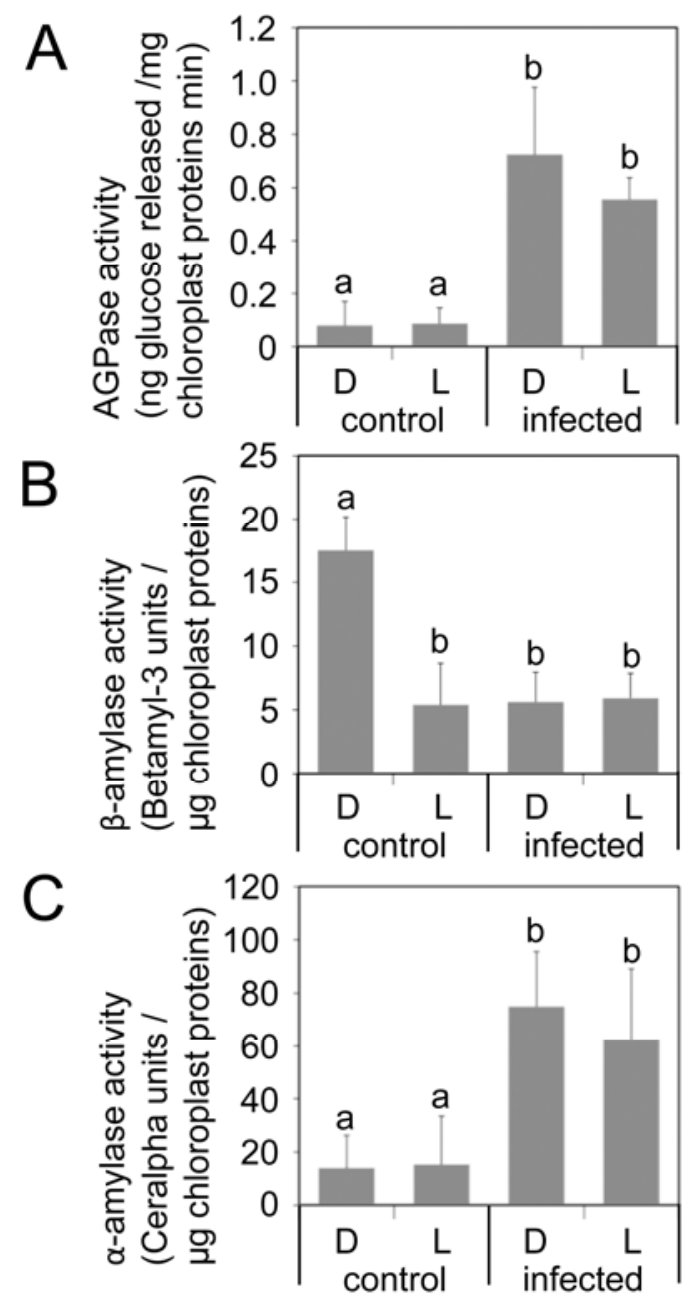

Fig. 5. Activity of A, ADP-glucose pyrophosphorylase (AGPase); B, $\beta$ amylase; and $\mathbf{C}, \alpha$-amylase in control and Plasmopara viticola-infected grapevine leaves (7 days postinoculation [dpi]). Leaves were collected during the light period (L) and at the end of the dark period (D). Data correspond to the average of three biological replicates \pm standard deviation. Means with different letters $(\mathrm{a}, \mathrm{b})$ are significantly different $(P<0.05)$. lar in the dark and light periods and corresponded to the low value measured for control samples of the light period (Fig. 5B). $\alpha$-Amylase activity was more than threefold higher in infected than in control leaves for both sampling periods (Fig. 5C).

\section{Alteration of soluble sugar.}

To verify whether infection leads to a global deregulation of the sugar metabolism, ${ }^{13} \mathrm{C}$-spectroscopy was used to draw up and compare the profiles of soluble metabolites in control and $P$. viticola-infected leaves (6 dpi, end of the dark period). ${ }^{13} \mathrm{C}$ nuclear magnetic resonance (NMR) spectra showed that fructose and glucose seemed more abundant and sucrose less present in infected compared with control leaves (Supplementary Fig. S2). Malic acid was the most abundant Krebs intermediate, and tartaric acid appeared particularly abundant in both control and infected leaves.

Next, high-performance anion-exchange chromatography with pulsed amperometric detection (HPAEC-PAD) was used to quantify glucose, fructose, and sucrose in samples over the course of infection. At the end of the dark period, glucose, fructose, and sucrose at approximately 9, 6, and $13 \mathrm{mg} / \mathrm{g}$ dry weight (DW), respectively, were detected in control leaves. No significant difference could be observed between control and infected leaves before 7 dpi (Fig. 6A). At 7 dpi, however, glucose and fructose concentrations increased significantly in infected leaves, while the sucrose level remained similar to that of control plants (Fig. 6A). For control leaves collected during the light period, the sugar concentrations varied for glucose, fructose, and sucrose at approximately $11,8.5$, and 30
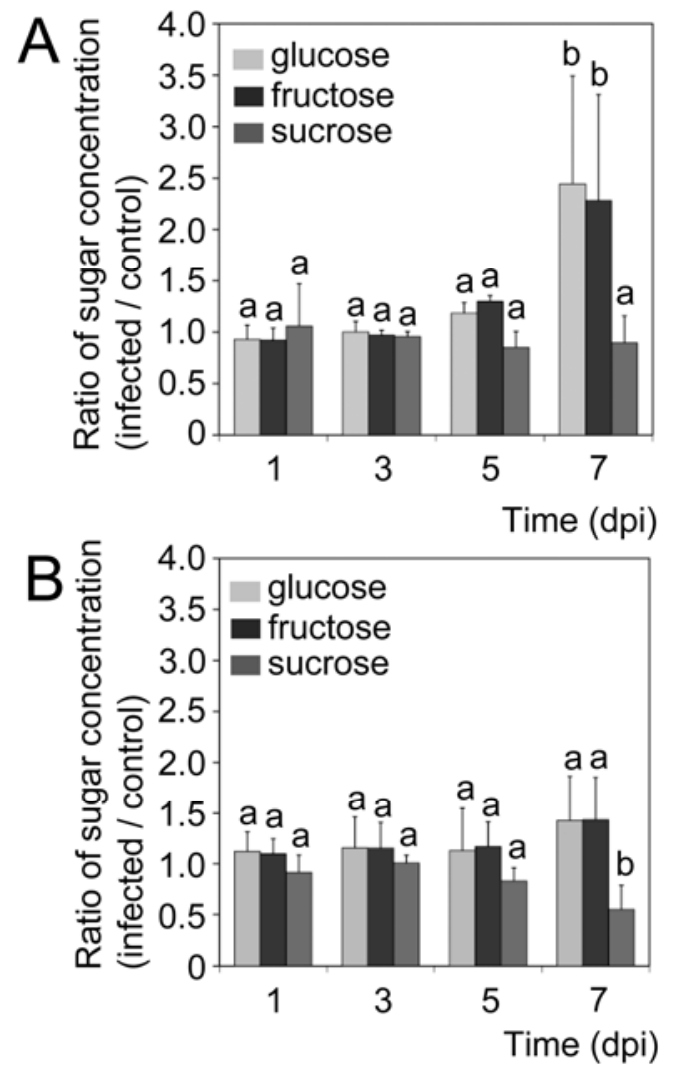

Fig. 6. Ratios of glucose, fructose, and sucrose concentrations of Plasmopara viticola-infected versus control grapevine leaves. Samples were collected from 1 to 7 days postinoculation (dpi) $\mathbf{A}$, at the end of the dark period or $\mathbf{B}$, during the light period and analyzed by high-performance anion-exchange chromatography with pulsed amperometric detection. Data correspond to the average of three independent biological repeats \pm standard deviation. Means with different letters $(a, b)$ are significantly different $(P<0.05)$. 
$\mathrm{mg} / \mathrm{g}$ DW, respectively. The concentrations were quite similar in infected leaves until $7 \mathrm{dpi}$, whereas sucrose concentration showed a 1.8-fold decrease in infected leaves compared with control leaves (Fig. 6B).

To further investigate the origin of the variations of the sugar content, the expression of genes encoding sucrose phosphate synthase and cell wall invertase, two enzymes implicated in the synthesis and degradation of sucrose, respectively, were followed using qRT-PCR analysis. The gene encoding sucrose phosphate synthase was repressed at $5 \mathrm{dpi}$ at the end of the dark period and at 7 dpi during both the light and dark periods (Fig. 4E). However, that encoding cell wall invertase was clearly induced from 5 dpi during both periods (Fig. 4F). These data fit well with those obtained in the microarray analysis (Table 1).

Finally, invertase activity was assessed in the insoluble fraction of leaf extracts (Fig. 7). At pH 4.5, optimum for cell wall invertases (Avigad 1982), no difference in activity could be measured between control and infected leaves. At $\mathrm{pH} 7.5$, however, a strong increase of invertase activity was observed in infected leaves from $5 \mathrm{dpi}$, independently of the sampling period. The invertase activities were also assessed in the soluble fraction of the leaf extracts but no significant difference was shown, whatever the $\mathrm{pH}$ conditions (data not shown).

\section{Trehalose accumulation.}

HPAEC-PAD also allowed trehalose analysis. It was only present in trace amounts in control leaves. In infected leaves, its concentration increased from 5 dpi to reach $2.41 \pm 1.1 \mathrm{mg} / \mathrm{g}$ DW and $5.16 \pm 4.07 \mathrm{mg} / \mathrm{g} \mathrm{DW}$ at $7 \mathrm{dpi}$ in samples collected in the dark and light periods, respectively.

The microarray analysis showed that the expression of the gene encoding TPS was repressed in infected leaves (Table 1), whereas that encoding trehalose 6-phosphate phosphatase was not differentially regulated (data not shown). The trehalase gene expression was induced from 5 dpi (Table 1; Fig. 8A). Trehalase activity was more than 10 times higher in infected leaves (7 dpi) for both sampling periods (Fig. 8B).

\section{Decrease in the photosynthetic efficiency and in chlorophyll levels.}

In infected leaves, Fv/Fm, the maximum efficiency of photosystem II (PSII), was reduced from 5 dpi in the infected area (Fig. 9A). Fv/Fm, the effective PSII quantum yield $\left(\Phi_{\mathrm{PSII}}\right)$, and

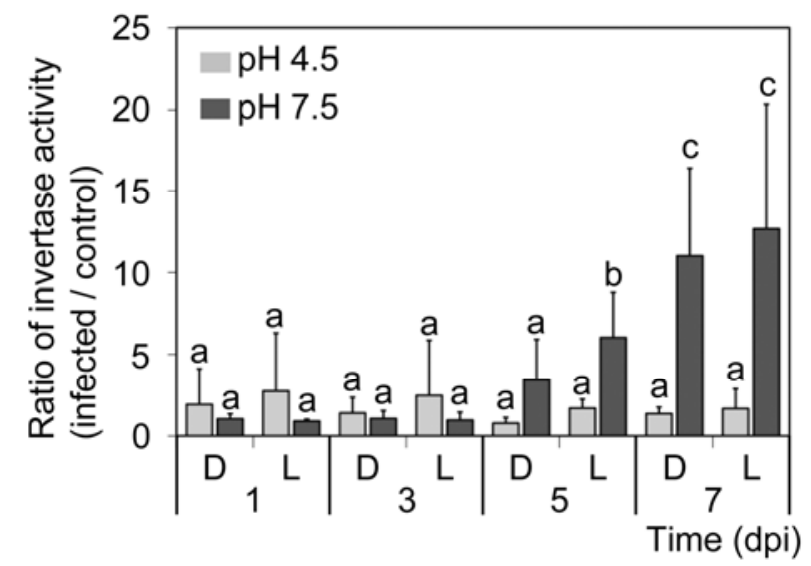

Fig. 7. Invertase activity measured at $\mathrm{pH} 4.5$ and 7.5. Ratios of enzyme activity in the insoluble fraction of leaf extracts from control versus Plasmopara viticola-infected grapevine samples collected at the end of the dark period (D) and during the light period (L). Data correspond to the average of three independent biological replicates \pm standard deviation. Means with different letters $(\mathrm{a}, \mathrm{b}, \mathrm{c})$ are significantly different $(P<0.05)$. photochemical and nonphotochemical quenching $\left(\mathrm{q}_{\mathrm{P}}\right.$ and $\left.\mathrm{q}_{\mathrm{N}}\right)$ were determined in the oil spots and adjacent areas of infected leaves (7 dpi) and in control leaves (Fig. 9B). The Fv/Fm was reduced to $0.63 \pm 0.06$ in the oil spots, compared with $0.76 \pm$ 0.02 in control leaves. It was accompanied by a decrease of $\Phi_{\text {PSII }}$ from $0.34 \pm 0.03$ to $0.19 \pm 0.04$ and of $q_{P}$ from $0.63 \pm$ 0.03 to $0.54 \pm 0.08$. Meanwhile, the $\mathrm{q}_{\mathrm{N}}$ value increased from $0.77 \pm 0.04$ to $0.84 \pm 0.03$. The measured parameters showed no significant difference between noninfected control leaves and green regions showing no symptoms (adjacent to oil spots) in infected leaves (Fig. 9B).

In addition, the chlorophyll content was determined in control and infected leaves at $7 \mathrm{dpi}$. In control leaves, the total chlorophyll concentration was $24.8 \pm 1.8 \mathrm{mg} / \mathrm{g} \mathrm{FW}$, and it was reduced to $17.3 \pm 0.8 \mathrm{mg} / \mathrm{g} \mathrm{FW}$ in infected leaves, mainly due to a decrease of the chlorophyll a level (Fig. 9C).

\section{DISCUSSION}

In leaves, starch accumulates during the day and is degraded during the dark period. This dynamic is regulated, so that starch catabolism is almost complete at the end of the night. Plants are able to adjust this finely tuned pattern in response to changes in environmental conditions. In P. viticola-infected grapevine leaves, we observed an abnormally high starch accumulation at the end of the dark period, suggesting major modifications in starch metabolism regulation. Depending on the pathosystems, a decrease (Horst et al. 2008; Judelson et al. 2009; Storr and Hall 1992) or an increase (Ji et al. 2009; Kim
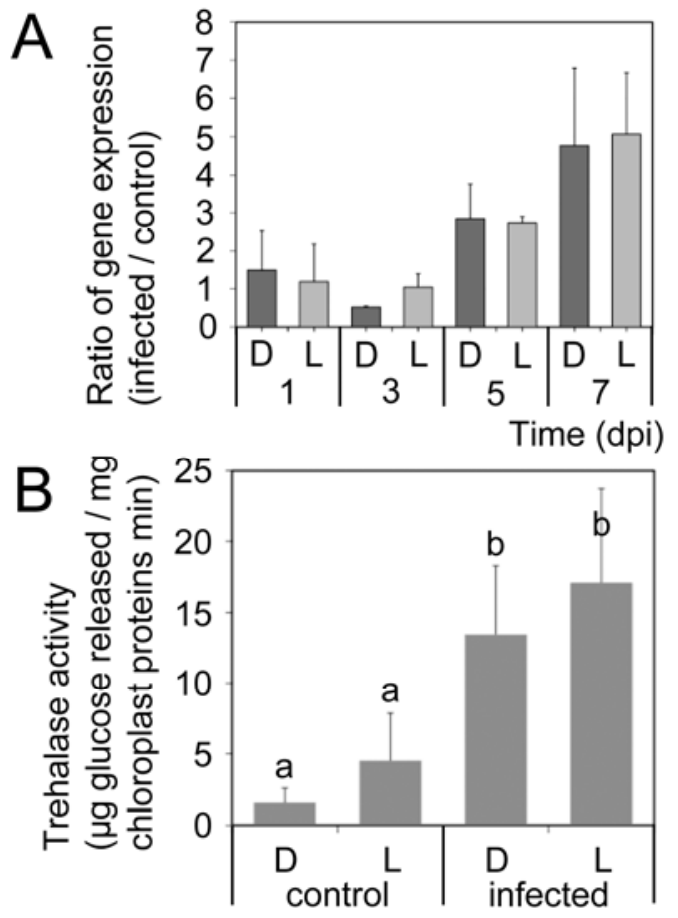

Fig. 8. A, Trehalase gene expression and B, enzyme activity. A, Expression levels obtained for infected leaves were normalized with respect to VATP16 and $60 S R P$ expression and related to the corresponding values of control leaves. Samples were collected during the light period (L) or at the end of the dark period (D) during a time course of grapevine leaf infection by Plasmopara viticola (1 to 7 days postinoculation [dpi]). Data correspond to the average of three independent biological replicates \pm standard deviation. B, Quantification of the trehalase activity was performed in control and $P$. viticola-infected grapevine leaves at $7 \mathrm{dpi}$. Bars represent the average of three biological replicates \pm standard deviation. Means with different letters $(\mathrm{a}, \mathrm{b})$ are significantly different $(P<$ $0.05)$. 
et al. 2009; Rodríguez et al. 2010) of the starch content was observed in some plant-biotrophic pathogen interactions.

A microarray analysis revealed that the expression of several genes related to the carbohydrate metabolism was modified in infected leaves. The expression of genes encoding starch-degrading enzymes (i.e., a grapevine isoform of a phosphoglucan water, dikinase, and $\beta$-amylase) were repressed. PWD plays an essential role in starch degradation because the phosphorylation of semicrystalline starch particles is required for the subsequent degradation by other enzymes (Kötting et al. 2005; Ritte et al. 2002, 2004; Smith and Stitt 2007). $\beta$-Amylase is an exo-acting enzyme that degrades the $\alpha$-1,4-glycosidic bonds from the nonreducing end of the starch molecules, releasing maltose. It plays a major role in the degradation of leaf starch in potato leaves (Scheidig et al. 2002) and probably in other species (Lloyd et al. 2005). These microarray results suggest that starch catabolism is affected in P. viticola-infected leaves.

Surprisingly, we have observed a high induction of the expression of a gene encoding $\alpha$-amylase, an endo-acting enzyme that degrades 1,4-glycosidic bonds to release malto-oligosaccharides. This enzyme is mostly described in the context of sink tissues, as potato tubers or cereal endosperm, but con- flicting reports exist about its function in foliar tissues (Llyod et al. 2005). The rice isoform AMY1 was shown to have a significant function in leaf starch degradation (Asatsuma et al. 2005). It seems to play no essential role in Arabidopsis (Yu et al. 2005), except in leaves during senescence or infection with Pseudomonas syringae pv. tomato, where the gene encoding $\alpha$-amylase A1 is induced (Doyle et al. 2007). Up to now, to our knowledge, no data on the function and the importance of the amylase isoforms in grapevine leaf starch metabolism were available. In our study, qRT-PCR confirmed that the expression of the $\beta$-amylase gene was repressed in infected leaves, whereas it was clearly induced for the $\alpha$-amylase gene. Concerning enzyme activities, the $\beta$-amylase activity was reduced in infected leaves at the end of the dark period whereas it remained unchanged for the light period. The activity of $\alpha$-amylase was induced in infected leaves for both sampling periods. These results suggest that, in Plasmopara viticola-infected leaves, $\alpha$-amylase replaces $\beta$-amylase for starch degradation. The observed starch accumulation might result from a lower efficiency of $\alpha$-amylase to degrade starch.

We have also studied enzymes involved in starch synthesis, including the key enzyme AGPase. The microarray analysis,
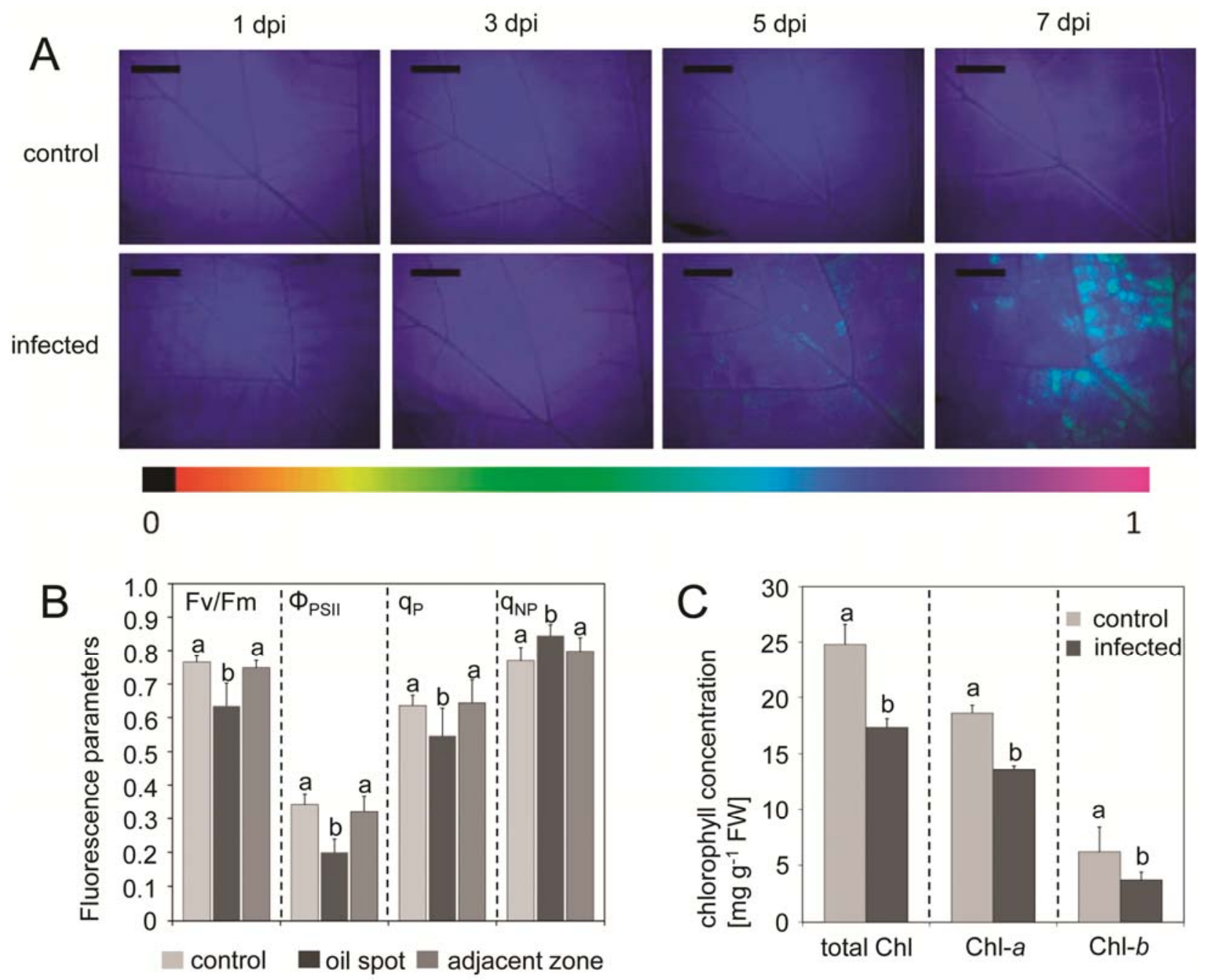

Fig. 9. Photosynthetic parameters in control and Plasmopara viticola-infected leaves. A, Imaging of the maximum efficiency of PSII (Fv/Fm); B, values for Fv/Fm, effective PSII quantum yield $\left(\Phi_{\mathrm{PSII}}\right)$, and photochemical $\left(\mathrm{q}_{\mathrm{P}}\right)$ and nonphotochemical $\left(\mathrm{q}_{\mathrm{N}}\right)$ quenching parameters; and $\mathbf{C}$, chlorophyll concentrations in control and $P$. viticola-infected leaves (7 days postinoculation [dpi]). A, Representative false-color images of control and $P$. viticola-infected leaves during the course of infection ( 1 to $7 \mathrm{dpi}$ ). Scale represents $0.5 \mathrm{~cm}$. B, Measurements were performed in infected (oil spots and adjacent area without symptoms) and control leaves. Data correspond to the average of 35 measurements \pm standard deviation. Means with different letters $(a$, b) are significantly different $(P<$ $0.05)$. C, Data correspond to the average of three biological replicates \pm standard deviation. Means with different letters $(\mathrm{a}, \mathrm{b})$ are significantly different $(P<$ $0.05)$. 
confirmed by qRT-PCR, revealed that the expression of the gene encoding the large subunit 1 of AGPase was repressed in infected leaves. However, it was not correlated to a reduction but an increase of the enzyme activity. In Arabidopsis, changes in the transcription of this gene do not systematically lead to a change in protein abundance or enzyme activity because a strong post-translational regulation is important to control starch metabolism (Gibon et al. 2004; Lu et al. 2005; Smith et al. 2004). Therefore, in P. viticola-infected leaves, starch accumulation could result from the increase of AGPase activity and alteration of starch degradation.

At $7 \mathrm{dpi}$, both glucose and fructose levels were higher in infected than in control leaves at the end of the dark period. Microorganisms can induce changes in soluble sugar concentrations (Horst et al. 2008; Ji et al. 2009; Jobic et al. 2007; Rodriguez et al. 2010). For example, an increase in soluble sugars was observed in Arabidopsis, wheat, or tobacco infected by Albugo candida, Puccinia graminis, or Phytophthora nicotianae, respectively (Chou et al. 2000; Scharte et al. 2005; Tang et al. 1996; Wright et al. 1995). In plant-pathogen interactions, sugars play several roles: energy source to fuel the activation of defense reactions, regulators of gene expression (sugar signaling), and nutrients. They can induce pathogenesisrelated (PR) proteins (Roitsch 1999) and sink-specific genes (such as invertase) and repress source-specific genes, such as the chlorophyll subunit $\mathrm{a} / \mathrm{b}$ binding protein and Rubisco (Rolland et al. 2002). In our case, because sugars accumulate just before sporulation, a role in plant defense seems uncertain but they certainly serve as nutrients for the pathogen.

Sucrose is the main form of sugar transported in plants and invertase catalyzes its cleavage into glucose and fructose. At 7 dpi, infected leaves showed a low level of sucrose, but only during the light period. However, we have shown an increase in invertase activity in the insoluble fraction after $3 \mathrm{dpi}$, independently of the sampling period. Therefore, one could expect a lower sucrose level at the end of the dark period and a higher level of glucose and fructose during the light period compared with the obtained results. Such discrepancies might reflect distinct day and night carbohydrate metabolism of Plasmopara viticola. It is consistent with developmental events such as sporulation, which preferentially occurs in the dark. An increase in cell-wall invertase activity seems to be a common feature in plants infected by viruses (Herbers et al. 2000), bacteria (Sturm and Chrispeels 1990), necrotrophic fungi (Benhamou et al. 1991), and biotrophic fungi (Chou et al. 2000; Fotopoulos et al. 2003; Hall and Williams 2000; Roitsch et al. 2003; Scholes et al. 1994; Sutton et al. 2007; Voegele et al. 2006). In grapevine, Hayes and associates (2010) have reported the induction of a cell-wall invertase gene expression in downy and powdery mildew-infected leaves. Because host and pathogen possess invertases, it is difficult to establish which one is activated during the interaction. Few works stated the plant or pathogen origin of invertases during interactions. An immunological approach was used to show the involvement of a fungal invertase in sunflower-Sclerotinia sclerotiorum and grapevine-Botrytis cinerea interactions (Jobic et al. 2007; Ruiz and Ruffner 2002). In the Vicia faba-U. fabae interaction, Voegele and associates (2006) have observed an increase of both plant and pathogen invertase gene expression. In our pathosystem, because $P$. viticola is an obligate intra-tissular biotroph pathogen, we cannot state whether the invertase activity determinant for the carbohydrate changes observed is of plant or pathogen origin. The increase in the invertase activity might be linked to the starch accumulation observed. Indeed, Fernie and associates (2001) have reported a correlation between an increase in invertase activity and starch synthesis in potato discs treated by palatinose.
The invertase detected in the insoluble fraction had an alkaline optimum $\mathrm{pH}$, whereas major plant invertases activated during a compatible interaction with biotrophic fungi are extracellular acid enzymes (Roitsch et al. 2003). To our knowledge, only one study has reported an alkaline cell-wall invertase in rice cell suspensions but not in a context of plantpathogen interaction (Hsiao et al. 2002). Thus, further experiments would be required in order to characterize the alkaline invertase found in P. viticola-infected grapevine leaves.

An increasing level of the disaccharide trehalose was observed in $P$. viticola-infected leaves. Brem and associates (1986) have reported a depletion of sucrose and a diversion of glucose to trehalose in $P$. viticola-infected leaves but it was after the beginning of sporulation. In most plants, trehalose is found only in trace amounts (Goddjin et al. 1997; Paul et al. 2008); however, there is growing interest in its metabolic pathway because it has effects on growth, development, metabolism, and stress resistance and it may play an important regulatory role in carbohydrate metabolism or signaling (Goddjin and Smeekens 1998; Paul 2007). In Arabidopsis, it activates ApL3 gene expression, AGPase activity, and starch accumulation (Fritzius et al. 2001; Kolbe et al. 2005; Ramon et al. 2007; Wingler et al. 2000). In soybean, it affects sucrose synthase and invertase activities (Müller et al. 1998). The trehalose precursor, trehalose 6-phosphate (T6P), also regulates starch biosynthesis via post-translational redox modification of AGPase (Kolbe et al. 2005; Lunn et al. 2006; Schluepmann et al. 2003); therefore, the increase in trehalose concentration-or T6P-during leaf infection might be involved in the starch accumulation observed. Few studies have reported a trehalose accumulation in plant organs infected by pathogens (Fernandez et al. 2010). In Arabidopsis, trehalose activates the expression of genes encoding a defense-related transcription factor and a PR protein (Schluepmann et al. 2004). In wheat, it confers a protection against the necrotrophic agent Blumeria graminis, associated with papilla deposition, $\mathrm{H}_{2} \mathrm{O}_{2}$ production, and an increase in phenylalanine ammonia lyase and peroxidase activities (Reignault et al. 2001; Renard-Merlier et al. 2007). It could also act as a virulence factor in some interactions such as Arabidopsis thaliana-Plasmodiophora brassicae (Brodmann et al. 2002). In this case, a trehalase activity was also detected and supposed to be produced by the plant to counteract trehalose accumulation. In our pathosystem, it is unclear whether trehalose is produced by the plant or by the oomycete. Its accumulation was correlated to increasing trehalase gene expression and enzyme activity. The accumulated trehalose might be degraded by the plant as a regulation process or by the pathogen for nutrition.

Starch and sugar metabolic pathways are known to be regulated by the circadian rhythm (Graf et al. 2010; Lu et al. 2005; Smith and Stitt 2007; Smith et al. 2004; Zeeman et al. 2007); therefore, we have studied the gene expression and enzyme activities in both darkness and light. In our conditions, the day and night regulation of gene expression was visible in control samples and was maintained in infected leaves. However, it is not visible on the graphs because data of infected leaves were related to the corresponding values of control leaves. For enzymatic activities, only $\beta$-amylase showed a circadian regulation in control leaves. As previously described, the diurnal regulation of gene expression does not always directly impact the protein level, underlining the importance of post-translational regulation (Lu et al. 2005; Smith et al. 2004).

We have observed a repression of the expression of genes encoding chlorophyll synthase, chlorophyll a/b binding protein, and Rubisco and an induction of chlorophyllase gene expression in infected leaves. This was associated with a decrease of the leaf chlorophyll content. Moreover, measurement 
of chlorophyll fluorescence indicated a reduction of the Fv/Fm associated with an increase in the $\mathrm{q}_{\mathrm{N}}$ values in the oil spots, whereas both parameters where similar in control leaves and the green area surrounding oil spots. Moriondo and associates (2005) also described a similar Fv/Fm in uninfected leaves and the green area of downy mildew-infected leaves. However, they did not determine it in oil spots. Several studies have shown that rates of photosynthesis are reduced near areas infected with pathogens (Berger et al. 2007; Chou et al. 2000; Scharte et al. 2005; Swarbrick et al. 2006; Zou et al. 2005) and can be associated with a loss of chlorophyll, as observed in leaves infected by rusts and downy and powdery mildew (Ahmad et al. 1983; Scholes et al. 1994; Wright et al. 1995). In oat leaves infected with crown rust, Scholes and Rolfe (1996) also observed reduced photosynthesis efficiency in infected area and an increase of $\mathrm{q}_{\mathrm{N}}$ values that they associated with a high demand for ATP. In stress situations, increases in $\mathrm{q}_{\mathrm{N}}$ values are often accompanied by photoinactivation of PSII reaction centers leading to a dissipation of excitation energy as heat rather than as photochemistry (Melis 1999). In our conditions, the repression of genes encoding the Rubisco large subunit and chlorophyll $\mathrm{a} / \mathrm{b}$ binding protein may also explain the reduction of the photosynthetic efficiency. A lower rate in photosynthesis is associated with an increase in invertase activity, a hexose accumulation, and a downregulation of photosynthetic gene expression. These events reflect a source to sink transition in carbohydrate production and partitioning within host tissues as described before for compatible interactions (Abood and Lösel 2003; Chou et al. 2000; Hall and Williams 2000; Scholes et al. 1994; Swarbrick et al. 2006; Tang et al. 1996).

In conclusion, in Plasmopara viticola-infected leaves, we have described, for the first time, an abnormal starch accumulation associated with an increase of starch synthesis (increase in AGPase activity) and modifications in the starchdegradation pathway (increase in $\alpha$-amylase activity and decrease in $\beta$-amylase activity). These events occur together with a source-to-sink transition marked by an increase in hexose levels and invertase activity and a reduction of photosynthetic capacity. Altogether, these results highlight a dramatic alteration of carbohydrate metabolism. All these modifications occurred at the end of infection when the leaves were highly colonized and may be associated with the presporulation stage. The originality of this study remains in the identification of key events from gene expression toward the sugar dynamic.

\section{MATERIALS AND METHODS}

\section{Biological material.}

Grapevine (Vitis vinifera L. 'Marselan') herbaceous cuttings were grown as previously described (Allègre et al. 2007) in a greenhouse at $25 \pm 4$ and $18 \pm 7^{\circ} \mathrm{C}$ (day and night, respectively).

The $P$. viticola strain was maintained on Marselan plants and inoculation was performed as previously described (Allègre et al. 2009). Briefly, the lower side of leaves was sprayed with a suspension of $10^{4}$ sporangia/ml in distilled water, incubated overnight at a relative humidity of $100 \%$, and placed in the conditions described above. For mock inoculation used as a control, the leaf lower surface was sprayed with water and the plants placed in the conditions described above.

For all experiments, the third and fourth (from the shoot base) leaves of control and inoculated plants were harvested at the end of the dark period or after $10 \mathrm{~h}$ of light. For mRNA, DNA, soluble sugar, total protein and starch extractions, and aniline blue staining, leaves were collected at 1,3,5, and 7 dpi and immediately frozen in liquid nitrogen. For the other experiments, samples were collected at 6 or 7 dpi. Six plants were used per treatment and time point and three biological repetitions were performed.

\section{Visualization of pathogen development.}

Leaf discs $(7 \mathrm{~mm})$ from infected and control plants were harvested at $1,3,5$, and $7 \mathrm{dpi}$ and $P$. viticola was visualized using blue aniline staining as previously described (Trouvelot et al. 2008).

\section{Transmission electron microscopy.}

Samples were prepared and examined as previously described (Trouvelot et al. 2008). For each leaf, sections were cut in three different zones along the leaf fragment. At least $60 \mathrm{sec}-$ tions were observed per zone.

\section{Leaf starch staining by lugol.}

Leaves were clarified in absolute ethanol $\left(10 \mathrm{~min}\right.$ at $\left.90^{\circ} \mathrm{C}\right)$, rinsed in water, incubated for $10 \mathrm{~min}$ in diluted lugol solution (1:16 [vol/vol]) (Sigma-Aldrich, St Louis), rinsed twice, and photographed immediately.

\section{Starch extraction and quantification.}

Starch was extracted and quantified from $500 \mathrm{mg}$ of leaves according to Smith and Zeeman (2006).

\section{NMR spectrometry.}

Perchloric acid extracts were prepared using $5 \mathrm{~g}$ of leaves according to the method described by Aubert and associates (1996) and NMR spectrometry was performed as described by Jobic and associates (2007).

\section{HPAEC-PAD analysis of soluble sugars.}

Samples were ground in liquid nitrogen and lyophilized. The powder $(50 \mathrm{mg}$ ) was treated by $1 \mathrm{ml}$ of $80 \%$ ethanol (30 $\left.\min , 80^{\circ} \mathrm{C}\right)$ in an ultrasonic bath. After centrifugation $(10 \mathrm{~min}$, $15,000 \times g), 10 \mu \mathrm{l}$ of supernatant was injected on an ICS 3000 Dionex instrument (Dionex Corp., Sunnyvale, CA, U.S.A.). The sugar contents were determined by HPAEC-PAD using a guard and analytical column CarboPac PA100 (Dionex P/N043055), according to Dionex instructions (Dionex Application Note 122 [2004]).

\section{Total protein extraction and enzyme activities.}

Proteins were extracted as described by Dancer and associates (1990). The protein concentration of the extracts was estimated according to the method of Bradford (1976). Invertase activities of soluble and insoluble fractions were assayed as described by Dancer and associates (1990). Trehalase activity of the soluble fraction was quantified according to Brodmann and associates (2002).

\section{Chloroplast protein extraction.}

Chloroplast proteins were extracted from enriched chloroplast fractions according to a protocol modified from Elias and Givan (1978) and Triboush and associates (1998). Leaves (10 g) were ground with sand, added by $100 \mathrm{ml}$ of extraction buffer (50 mM HEPES-KOH [pH 8.0], $330 \mathrm{mM}$ sorbitol, 5 $\mathrm{mM}$ ascorbic acid, $5 \mathrm{mM}$ cysteine, $2 \mathrm{mM}$ EDTA, $1 \mathrm{mM}$ PMSF, and $2.5 \%$ [wt/vol] polyvinyl-polypyrrolidone), filtered through two layers of cloth (mesh size $35 \mu \mathrm{m})$, and centrifuged $(200 \times$ $g, 20 \mathrm{~min}, 4^{\circ} \mathrm{C}$ ). The supernatant was transferred to a new tube and centrifuged $\left(6,000 \times g, 25 \mathrm{~min}, 4^{\circ} \mathrm{C}\right)$. The pellet was washed with 1 vol of washing buffer (50 mM HEPES-KOH [pH 8.0], $330 \mathrm{mM}$ sorbitol, $2 \mathrm{mM}$ EDTA, and $1 \mathrm{mM}$ PMSF), resuspended in 1 vol of protein buffer $(10 \mathrm{mM}$ HEPES-KOH 
[pH 8.0], $5 \mathrm{mM} \mathrm{MgCl}_{2}$, and $1 \mathrm{mM}$ PMSF), incubated on ice for $10 \mathrm{~min}$, and centrifuged $\left(10,000 \times g, 25 \mathrm{~min}, 4^{\circ} \mathrm{C}\right)$. Proteins of the supernatant were concentrated using Microcon spin columns (cut-off $30 \mathrm{kDa}$; Millipore, Billerica, MA, U.S.A.). The protein concentration of the samples was estimated according to the method of Bradford (1976).

Ceralpha and Betamyl-3 kits (Megazyme, Wicklow, Ireland) were used to determine $\alpha$ - and $\beta$-amylase activities in chloroplast protein extracts diluted in the kit's extraction buffer $(1: 10$ [vol/vol]). The release of $p$-nitrophenol from the specific substrates was quantified according to the manufacturer's instructions. The AGPase activity in the pyrophosphorolysis direction was assessed as previously described (Tiessen et al. 2002).

\section{RNA extraction.}

Total RNA was extracted from $500 \mathrm{mg}$ of ground leaves as described by Reid and associates (2006). DNA contaminations were removed with the DNase 1-Kit (Sigma-Aldrich) according to the manufacturer's instructions. The concentration and purity of RNA extracts were determined by spectrophotometry. For microarray analysis, the quality was verified using an Agilent 2100 Bioanalyzer (Agilent Technologies, Santa Clara, CA, U.S.A.).

Total RNA $(4 \mu \mathrm{g})$ was used to synthesize the first-strand cDNA using the SuperScript III Reverse Transcriptase Kit (Invitrogen, Carlsbad, CA, U.S.A.) with a 1:1 mixture of Oligo$\mathrm{dT}$ and random hexamer primers following the kit's technical notice.

\section{Microarray analysis.}

The microarray analysis was performed at the University of Verona (Italy) on a NimbleGen V. vinifera chip (Roche NimbleGen, Madison, WI, U.S.A.). This array was based on the $12 \mathrm{X}$ grapevine genome assembly produced by the French-Italian consortium. In all, 29,582 transcripts were analyzed with four probes per transcript (one replicate per probe). RNA samples for hybridization were extracted from control or infected leaves ( $7 \mathrm{dpi}$, end of the dark period), as described above, including three independent biological replicates. cDNA labeled with Cyanine 3 (Cy3) was produced from total RNA $(1 \mu \mathrm{g})$ and hybridized as indicated in the NimbleGen array user guide. The array was scanned using the Axon GenePix 4400A Microarray scanner (Molecular Devices, Sunnyvale, CA, U.S.A.) and images were analyzed using the Nimblescan software (Roche NimbleGen). Fluorescence data were extracted using the robust multi-array algorithm with quantile normalization (Supplementary Table S2).

Student's $t$ test and statistical analysis of microarrays method (two-class unpaired test) (Tusher et al. 2001) were used to identify differentially expressed genes (fold change $<0.5$ [repressed] or $>2$ [induced]; $P<0.05$; false discovery rate $<$ $5 \%]$.

\section{Primer design and validation.}

Primer pairs were designed (Supplementary Table S3) using PerlPrimer software (Marshall 2004) and the sequence data of $V$. vinifera 'Pinot noir' (Jaillon et al. 2007) provided by the Genoscope Grape Genome Browser. All primers were examined for their target specificity by end-point PCR and the products sequenced by the Sanger method (Genoscreen, Lille, France).

\section{qRT-PCR.}

The ABsolute QPCR SYBR Green ROX Mix (Thermo Fisher Scientific, Waltham, MA, U.S.A.) was used with a final primer concentration of $500 \mathrm{nM}$ and $5 \mathrm{ng}$ of total cDNA. The thermal cycling profile was: $95^{\circ} \mathrm{C}$ for $15 \mathrm{~min}$ and 45 cycles at $95^{\circ} \mathrm{C}$ for $20 \mathrm{~s}, 60^{\circ} \mathrm{C}$ for $30 \mathrm{~s}$, and $72^{\circ} \mathrm{C}$ for $30 \mathrm{~s}$ (LightCycler480; Roche Applied Science, Penzberg, Germany). Each real-time assay was tested in a dissociation protocol to ensure that the amplicon was a single product. Amplification efficiency for each sample was calculated from the fluorescence raw data with the LinRegPCR program (Ruijter et al. 2009).

Samples were treated in technical triplicates and the mean values of cycle threshold $(\mathrm{Ct})$ and efficiency were used for further analysis. VATP16 and 60SRP ( L18e) were used as internal control genes (Gamm et al. 2011). Fold change in RNA expression was estimated using $\mathrm{Ct}$ by the $\Delta \Delta \mathrm{Ct}$ method (Livak and Schmittgen 2001).

\section{Pathogen quantification.}

Pathogen quantification was performed as described before (Silvar et al. 2005; Valsesia et al. 2005). DNA was extracted from control and infected leaves and $P$. viticola sporangia according to Porebski and associates (1997). DNA (100 ng) was used in a qRT-PCR mix with the ABsolute QPCR SYBR Green ROX Mix (Thermo Scientific), applying a final primer concentration of $500 \mathrm{nM}$. Pathogen and plant DNA contents were quantified using a $P$. viticola actin primer and a $V$. vinifera HT5 primer pair (Hayes et al. 2010; Schmidlin et al. 2008), respectively. The thermal cycling profile using a LightCycler480 (Roche Applied Science) was as described above.

\section{Chlorophyll analysis.}

The leaf chlorophyll a fluorescence was quantified on attached leaves using an IMAGING-PAM Chlorophyll Fluorometer (Walz, Effeltrich, Germany). Measurements were performed on the central parts of the leaf adaxial side after preconditioning in the dark. From these measurements, several fluorescence parameters were calculated according to Schreiber and associates (1986) and Genty and associates (1989): $\Phi_{\text {PSII }}$ and $\mathrm{Fv} / \mathrm{Fm}$. $\Phi_{\mathrm{PSII}}$ represents the number of electrons transported by a PSII reaction center per mole of quanta absorbed by PSII and Fv/Fm is the ratio of variable to maximal fluorescence. In addition, both $\mathrm{q}_{\mathrm{P}}$ and $\mathrm{q}_{\mathrm{N}}$ were calculated according to van Kooten and Snel (1990). On each image, the values of the selected fluorescence parameters were averaged. Images of $\Phi_{\text {PSII }}$ were displayed with the help of a false color code ranging from 0.000 (black) to 1.000 (pink).

For chlorophyll quantification, $3 \mathrm{~g}$ of leaves was ground in a mortar with sand and calcium carbonate and extracted with 20 $\mathrm{ml}$ of $95 \%$ methanol. The sample was filtered and analyzed by spectrometry at 645 and $663 \mathrm{~nm}$ (Hitachi U-2001 spectrophotometer, Hitachi Scientific Instruments, Mountain View, CA, U.S.A.), and the levels of chlorophylls were determined according to Wellburn and Lichtenthaler (1984).

\section{Statistical analysis.}

Data obtained for pathogen, carbohydrate, and chlorophyll quantification; enzyme activities; and chlorophyll fluorescence measurement were analyzed by one-way analysis of variance and means were compared using Fisher's least significant difference test to detect significant differences $(P<0.05)$ between treatments. All analyses were performed with the statistical program STATGRAPHICS (release 5.1; Manugistic, Inc., Rockville, MD, U.S.A.).

\section{ACKNOWLEDGMENTS}

This work received the financial support of the Conseil Régional de Bourgogne, the Bureau Interprofessionnel des Vins de Bourgogne (BIVB), and the Bureau Interprofessionnel des Vins de Champagne (CIVC). We thank O. Fernandez (University of Reims, France), N. Sicard (IUT Dijon, France), A. Ferrarini (University of Verona, Italy), G. Aubert, and M. Sanchez (INRA Dijon, France) for technical support. 


\section{LITERATURE CITED}

Abood, J. K., and Losel, D. M. 2003. Changes in carbohydrate composition of cucumber leaves during the development of powdery mildew infection. Plant Pathol. 52:256-265.

Ahmad, I., Farrar, J. F., and Whitbread, R. 1983. Photosynthesis and chloroplast functioning in leaves of barley infected with brown rust. Physiol. Mol. Plant Pathol. 23:411-419.

Allègre, M., Daire, X., Héloir, M. C., Trouvelot, S., Mercier, L., Adrian, M., and Pugin, A. 2007. Stomatal deregulation in Plasmopara viticolainfected grapevine leaves. New Phytol. 173:832-840.

Allègre, M., Héloir, M. C., Trouvelot, S., Daire, X., Pugin, A., Wendehenne, D., and Adrian, M. 2009. Are grapevine stomata involved in the elicitorinduced protection against downy mildew? Mol. Plant-Microbe Interact. 22:977-986.

Asatsuma, S., Sawada, C., Itoh, K., Okito, M., Kitajima, A., and Mitsui, T. 2005. Involvement of $\alpha$-amylase I-1 in starch degradation in rice chloroplasts. Plant Cell Physiol. 46:858-869.

Aubert, S., Gout, E., Bligny, R., Marty-Mazars, D., Barrieu, F., Alabouvette, J., Marty, F., and Douce, R. 1996. Ultrastructural and biochemical characterization of autophagy in higher plant cells subjected to carbon deprivation: Control by the supply of mitochondria with respiratory substrates. J. Cell Biol. 133:1251-1263.

Avigad, G. 1982. Sucrose and disaccharides. Pages 217-347 in: Encyclopedia of Plant Physiology, New Series, 13A. F. A. Lowus and D. Tanner, eds. Springer Verlag, Berlin.

Benhamou, N., Grenier, J., and Chrispeels, M. J. 1991. Accumulation of beta-fructosidase in the cell walls of tomato roots following infection by a fungal wilt pathogen. Plant Physiol. 97:739-750.

Berger, S., Sinha, A. K., and Roitsch, T. 2007. Plant physiology meets phytopathology: Plant primary metabolism and plant-pathogen interactions. J. Exp. Bot. 58:4019-4026.

Bolton, M. D. 2009. Primary metabolism and plant defense: Fuel for the fire. Mol. Plant-Microbe Interact. 22:487-497.

Bradford, M. M. 1976. A rapid and sensitive method for the quantitation of microgram quantities of protein utilizing the principle of protein-dye binding. Anal. Biochem. 72:248-254.

Brem, S., Rast, D. M., and Ruffner, H. P. 1986. Partitioning of photosynthate in leaves of Vitis vinifera infected with Uncinula necator or Plasmopara viticola. Physiol. Mol. Plant Pathol. 29:285-291.

Brodmann, D., Schuller, A., Ludwig-Müller, J., Aeschbacher, R. A., Wiemken, A., Boller, T., and Wingler, A. 2002. Induction of trehalase in Arabidopsis plants infected with the trehalose-producing pathogen Plasmodiophora brassicae. Mol. Plant-Microbe Interact. 15:693-700.

Chou, H. M., Bundock, N., Rolfe, S. A., and Scholes, J. D. 2000. Infection of Arabidopsis thaliana leaves with Albugo candida (white blister rust) causes a reprogramming of host metabolism. Mol. Plant Pathol. 1:99113.

Dai, G. H., Andary, C., Mondolot-Cosson, L., and Boubals, D. 1995. Histochemical studies on the interaction between three species of grapevine, Vitis vinifera, V. rupestris and V. rotundifolia and the downy mildew fungus, Plasmopara viticola. Physiol. Mol. Plant Pathol. 46:177-188

Dancer, J., Hatzfeld, W. D., and Stitt, M. 1990. Cytosolic cycles regulate the turnover of sucrose in heterotrophic cell-suspension cultures of Chenopodium rubrum L. Planta 182:223-231.

Diez-Navajas, A. M., Wiedemann-Merdinoglu, S., Greif, C., and Merdinoglu, D. 2008. Nonhost versus host resistance to the grapevine downy mildew, Plasmopara viticola, studied at the tissue level. Phytopathology 98:776-780.

Doyle, E. A., Lane, A. M., Sides, J. M., and Mudgett, M. B. 2007. An $\alpha-$ amylase (At4g25000) in Arabidopsis leaves is secreted and induced by biotic and abiotic stress. Plant Cell Environ. 30:388-398.

Elias, B. A., and Givan, C. V. 1978. Density gradient and differential centrifugation methods for chloroplast purification and enzyme localization in leaf tissue. Planta 142:317-320.

Fernandez, O., Béthencourt, L., Quero, A., Sangwan, R. S., and Clément, C. 2010. Trehalose and plant stress responses: Friend or foe? Trends Plant Sci. 15:409-417.

Fernie, A. R., Roessner, U., and Geigenberger, P. 2001. The sucrose analog palatinose leads to a stimulation of sucrose degradation and starch synthesis when supplied to discs of growing potato tubers. Plant Physiol. 125:1967-1977.

Fotopoulos, V., Gilbert, M. J., Pittman, J. K., Marvier, A. C., Buchanon, A. J., Sauer, N., Hall, J. L., and Williams, L. E. 2003. The monosaccharide transporter gene, AtSTP4, and the cell-wall invertase, Atbetafruct 1, are induced in Arabidopsis during infection with the fungal biotroph Erysiphe cichoracearum. Plant Physiol. 132:821-829.

Fritzius, T., Aeschbacher, R., Wiemken, A., and Wingler, A. 2001. Induction of ApL3 expression by trehalose complements the starch-deficient
Arabidopsis mutant adg2-1 lacking ApL1, the large subunit of ADP-glucose pyrophosphorylase. Plant Physiol. 124:105-114.

Gamm, M., Héloir, M. C., Kelloniemi, J., Poinssot, B., Wendehenne, D., and Adrian, M. 2011 Identification of reference genes suitable for qRTPCR in grapevine and application for the study of the expression of genes involved in pterostilbene synthesis. Mol. Genet. Genomics 285:273-285.

Genty, B., Briantais, J. M., and Baker, N. R. 1989. The relationships between the quantum yield of photosynthetic electron transport and quenching of chlorophyll fluorescence. Biochim. Biophys. Acta 990:87-92.

Gibon, Y., Blaesing, O. E., Hannemann, J., Carillo, P., Höhne, M., Hendriks, J. H. M., Palacios, N., Cross, J., Selbig, J., and Stitt, M. 2004. A robot-based platform to measure multiple enzyme activities in Arabidopsis using a set of cycling assays: Comparison of changes of enzyme activities and transcript levels during diurnal cycles and in prolonged darkness. Plant Cell 16:3304-3325.

Gibson, S. I. 2005. Control of plant development and gene expression by sugar signaling. Curr. Opin. Plant Biol. 8:93-102.

Goddijn, O. J., and Smeekens, S. 1998. Sensing trehalose biosynthesis in plants. Plant J. 14:143-146.

Goddijn, O. J., Verwoerd, T. C., Voogd, E., Krutwagen, R. W., De Graaf, P. T., van Dun, K., Poels, J., Ponstein, A. S., Damm, B., and Pen, J. 1997. Inhibition of trehalase activity enhances trehalose accumulation in transgenic plants. Plant Physiol. 113:181-190.

Godt, D. E., and Roitsch, T. 1997. Regulation and tissue-specific distribution of mRNAs for three extracellular invertase isoenzymes of tomato suggests an important function in establishing and maintaining sink metabolism. Plant Physiol. 115:273-282.

Graf, A., Schlereth, A., Stitt, M., and Smith, A. M. 2010. Circadian control of carbohydrate availability for growth in Arabidopsis plants at night. Proc. Natl. Acad. Sci. U.S.A. 107:9458-9463.

Hall, J. L., and Williams, L. E. 2000. Assimilate transport and portioning in fungal biotrophic interactions. Aust. J. Plant Physiol. 27:549-560.

Hayes, M. A., Feechan, A., and Dry, I. B. 2010. Involvement of abscisic acid in the coordinated regulation of a stress-inducible hexose transporter $(V v H T 5)$ and a cell wall invertase in grapevine in response to biotrophic fungal infection. Plant Physiol. 153:211-221.

Herbers, K., Takahata, Y., Melzer, M., Mock, H. P., Hajirezaei, M., and Sonnewald, U. 2000. Regulation of carbohydrate partitioning during the interaction of Potato virus $Y$ with tobacco. Mol. Plant Pathol. 1:51-59.

Horst, R. J., Engelsdorf, T., Sonnewald, U., and Voll, L. M. 2008. Infection of maize leaves with Ustilago maydis prevents establishment of C4 photosynthesis. J. Plant Physiol. 165:19-28.

Hsiao, C. C., Fu, R. H., and Sung, H. Y. 2002. A novel bound form of plant invertase in rice suspension cells. Bot. Bull. Acad. Sin. 43:115-122.

Jaillon, O., Aury, J. M., Noel, B., Policriti, A., Clepet, C., Casagrande, A., Choisne, N., Aubourg, S., Vitulo, N., Jubin, C., Vezzi, A., Legeai, F., Hugueney, P., Dasilva, C., Horner, D., Mica, E., Jublot, D., Poulain, J., Bruyère, C., Billault, A., Segurens, B., Gouyvenoux, M., Ugarte, E. Cattonaro, F., Anthouard, V., Vico, V., Del Fabbro, C., Alaux, M., Di Gaspero, G., Dumas, V., Felice, N., Paillard, S., Juman, I., Moroldo, M., Scalabrin, S., Canaguier, A., Le Clainche, I., Malacrida, G., Durand, E., Pesole, G., Laucou, V., Chatelet, P., Merdinoglu, D., Delledonne, M., Pezzotti, M., Lecharny, A., Scarpelli, C., Artiguenave, F., Pè, M. E., Valle, G., Morgante, M., Caboche, M., Adam-Blondon, A. F., Weissenbach, J., Quétier, F., and Wincker, P. 2007. The grapevine genome sequence suggests ancestral hexaploidization in major angiosperm phyla. Nature 449:463-467.

Ji, X., Gai, Y., Zheng, C., and Mu, Z. 2009. Comparative proteomic analysis provides new insights into mulberry dwarf responses in mulberry (Morus alba L.) Proteomics 9:5328-5339.

Jobic, C., Boisson, A. M., Gout, E., Rascle, C., Fèvre, M., Cotton, P., and Bligny, R. 2007. Metabolic processes and carbon nutrient exchanges between host and pathogen sustain the disease development during sunflower infection by Sclerotinia sclerotiorum. Planta 226:251-265.

Judelson, H. S., Tani, S., and Narayan, R. D. 2009. Metabolic adaptation of Phytophthora infestans during growth on leaves, tubers and artificial media. Mol. Plant Pathol. 10:843-855.

Kim, J. S., Sagaram, U. S., Burns, J. K., Li, J. L., and Wang, N. 2009. Response of sweet orange (Citrus sinensis) to Candidatus Liberibacter asiaticus infection: Microscopy and microarray analyses. Phytopathology 99:50-57.

Koch, K. 2004. Sucrose metabolism: Regulatory mechanisms and pivotal roles in sugar sensing and plant development. Curr. Opin. Plant Biol. 7:235-246.

Kolbe, A., Tiessen, A., Schluepmann, H., Paul, M., Ulrich, S., and Geigenberger, P. 2005. Trehalose-6-phosphate regulates starch synthesis via post-translational redox-activation of ADP-glucose pyrophosphorylase. Proc. Natl. Acad. Sci. U.S.A. 102:11118-11123. 
Kötting, O., Pusch, K., Tiessen, A., Geigenberger, P., Steup, M., and Ritte, G. 2005. Identification of a novel enzyme required for starch metabolism in Arabidopsis leaves. Plant Physiol. 137:242-252.

Krapp, A., Hofmann, B., Schafer, C., and Stitt, M. 1993. Regulation of the expression of $r b c S$ and other photosynthetic genes by carbohydrates: A mechanism for the sink regulation of photosynthesis. Plant J. 3:817828

Livak, K. J., and Schmittgen, T. D. 2001. Analysis of relative gene expression data using real-time quantitative PCR and the 2(-delta delta C(T)) method. Methods 25:402-408.

Lloyd, J. R., Kossmann, J., and Ritte, G. 2005. Leaf starch degradation comes out of the shadows. Trends Plant Sci. 10:130-137.

Lu, Y., Gehan, J. P., and Sharkey, T. 2005. Daylength and circadian effects on starch degradation and maltose metabolism. Plant Physiol. 138:2280-2291.

Lunn, J. E., Feil, R. J., Hendriks, J., Gibon, Y., Morcuende, R., Osuna, D., Scheible, W. R., Carillo, R., Hajirezaei, M. R., and Stitt, M. 2006. Sugar-induced increases in trehalose 6-phosphate are correlated with redox activation of ADPglucose pyrophosphorylase and higher rates of starch synthesis in Arabidopsis thaliana. Biochem. J. 397:139-148.

Marshall, O. J. 2004. PerlPrimer: Cross-platform, graphical primer design for standard, bisulphite and real-time PCR. Bioinformatics 20:24712472.

Melis, A. 1999. Photosysteme II damage and repair cycle in chloroplasts: What modulates the rate of photodamage in vivo? Trends Plant Sci. 4:130-135.

Moriondo, M., Orlandini, S., Giuntoli, A., and Bindi, M. 2005. The effect of downy mildew and powdery mildew on grapevine (Vitis vinifera $\mathrm{L}$.) leaf gas exchange. J. Phytopathol. 153:350-357.

Müller, J., Boller, T., and Wiemken, A. 1998. Trehalose affects sucrose synthase and invertase activities in soybean (Glycine $\max$ L. Merr.) roots. J. Plant Physiol. 153:255-257.

Paul, M. J. 2007. Trehalose 6-phosphate. Curr. Opin. Plant Biol. 10:303309.

Paul, M. J., Primavesi, L. F., Jhurreea, D., and Zhang, Y. 2008. Trehalose metabolism and signaling. Annu. Rev. Plant Biol. 59:417-441.

Porebski, S., Grant Bailey, L., and Baum, B. R. 1997. Modification of a CTAB DNA extraction protocol for plants containing high polysaccharide and polyphenol components. Plant Mol. Biol. Rep. 15:8-15.

Ramon, M., Rolland, F., Thevelein, J. M., Van Dijck, P., and Leyman, B. 2007. ABI4 mediates the effects of exogenous trehalose on Arabidopsis growth and starch breakdown. Plant Mol. Biol. 63:195-206.

Reid, K. E., Olsson, N., Schlosser, J., Peng, F., and Lund, S. T. 2006. An optimized grapevine RNA isolation procedure and statistical determination of reference genes for real-time RT-PCR during berry development. BMC Plant Biol. 6:e27.

Reignault, P., Cogan, A., Muchembled, J., Lounes-Hadj Sahraoui, A., Durand, R., and Sancholle, M. 2001. Trehalose induces resistance to powdery mildew in wheat. New Phytol. 149:519-529.

Renard-Merlier, D., Randoux, B., Nowak, E., Farcy, F., Durand, R., and Reignault, P. 2007. Iodus 40, salicylic acid, heptanoyl salicylic acid and trehalose exhibit different efficacies and defence targets during a wheat/powdery mildew interaction. Phytochemistry 68:1156-1164.

Ritte, G., Lloyd, J. R., Eckermann, N., Rottmann, A., Kossmann, J., and Steup, M. 2002. The starch-related protein R1 is an $\alpha$-glucan, water dikinase. Proc. Natl. Acad. Sci. U.S.A. 99:7166-7171.

Ritte, G., Scharf, A., Eckermann, N., Haebel, S., and Steup, M. 2004. Phosphorylation of transitory starch is increased during degradation. Plant Physiol. 135:2068-2077.

Rodríguez, M., Taleisnik, E., Lenardon, S., and Lascano, R. 2010. Are Sunflower chlorotic mottle virus infection symptoms modulated by early increases in leaf sugar concentration? J. Plant Physiol. 167:11371144.

Roitsch, T. 1999. Source-sink regulation by sugar and stress. Curr. Opin. Plant Biol. 2:198-206.

Roitsch, T., Bittner, M., and Godt, D. E. 1995. Induction of apoplastic invertase of Chenopodium rubrum by D-glucose and a glucose analog and tissue-specific expression suggest a role in sink-source regulation. Plant Physiol. 108:285-294.

Roitsch, T., Balibrea, M. E., Hofmann, M., Proels, R., and Sinha, A. K. 2003. Extracellular invertase: Key metabolic enzyme and PR protein. J. Exp. Bot. 54:513-524.

Rolland, F., Moore, B., and Sheen, J. 2002. Sugar sensing and signaling in plants. Plant Cell 14:185-205.

Rolland, F., Baena-Gonzalez, E., and Sheen, J. 2006. Sugar sensing and signaling in plants: Conserved and novel mechanisms. Annu. Rev. Plant Biol. 57:675-709.

Ruijter, J. M., Ramakers, C., Hoogaars, W. M., Karlen, Y., Bakker, O., van den Hoff, M. J., and Moorman, A. F. 2009. Amplification efficiency: Linking baseline and bias in the analysis of quantitative PCR data.
Nucleic Acids Res. 37:45.

Ruiz, E., and Ruffner, H. P. 2002. Immunodetection of Botrytis-specific invertase in infected grapes. J. Phytopathol. 150:76-85.

Scharte, J., Schön, H., and Weis, E. 2005. Photosynthesis and carbohydrate metabolism in tobacco leaves during an incompatible interaction with Phytophthora nicotianae. Plant Cell Environ. 28:1421-1435.

Scheidig, A., Fröhlich, A., Schulze, S., Lloyd, J. R., and Kossmann, J. 2002. Downregulation of a chloroplast-targeted beta-amylase leads to a starch-excess phenotype in leaves. Plant J. 30:581-591.

Schluepmann, H., Pellny, T. I., van Dijken, A., Smeekens, S., and Paul, M. 2003. Trehalose 6-phosphate is indispensable for carbohydrate utilization and growth in Arabidopsis thaliana. Proc. Natl. Acad. Sci. U.S.A. 100:6849-6854.

Schluepmann, H., van Dijken, A., Aghdasi, M., Wobbes, B., Paul, M., and Smeekens, S. 2004. Trehalose mediated growth inhibition of Arabidopsis seedlings is due to trehalose-6-phosphate accumulation. Plant Physiol. 135:879-890.

Schmidlin, L., Poutaraud, A., Claudel, P., Mestre, P., Prado, E., SantosRosa, M., Wiedemann-Merdinoglu, S., Karst, F., Merdinoglu, D., and Hugueney, P. 2008. A stress-inducible resveratrol O-methyltransferase involved in the biosynthesis of pterostilbene in grapevine. Plant Physiol. 148:1630-1639.

Scholes, J. D., and Rolfe, S. A. 1996. Photosynthesis in localised regions of oat leaves infected with crown rust (Puccinia coronata): Quantitative imaging of chlorophyll fluorescence. Planta 199:573-582.

Scholes, J. D., Lee, P. J., Horton, P., and Lewis, D. H. 1994. Invertase: Understanding changes in the photosynthetic and carbohydrate metabolism of barley leaves infected with powdery mildew. New Phytol. 126:213222.

Schreiber, U., Schliwa, U., and Bilger, W. 1986. Continuous recording of photochemical and non-photochemical fluorescence quenching with a new type of modulation fluorometer. Photosynth. Res. 10:51-62.

Sheen, J., Zhou, L., and Jang, J. C. 1999. Sugars as signaling molecules. Curr. Opin. Plant Biol. 2:410-418.

Silvar, C., Díaz, J., and Merino, F. 2005. Real-time polymerase chain reaction quantification of Phytophthora capsici in different pepper genotypes. Phytopathology 95:1423-1429.

Sinha, A. K., Römer, U., Köckenberger, W., Hofmann, M., Elling, L., and Roitsch, T. 2002. Metabolizable and non-metabolizable sugars activate different signal transduction pathways in tomato. Plant Physiol. 128:1480-1489.

Smeekens, S. 2000. Sugar-induced signal transduction in plants. Annu. Rev. Plant Physiol. Plant Mol. Biol. 51:49-81.

Smith, A. M., and Stitt, M. 2007. Coordination of carbon supply and plant growth. Plant Cell Environ. 30:1126-1149.

Smith, A. M., and Zeeman, S. C. 2006. Quantification of starch in plant tissues. Nat. Protocol 1:1342-1345.

Smith, S. M., Fulton, D. C., Chia, T., Thorneycroft, D., Chapple, A., Dunstan, H., Hylton, C., Zeeman, S. C., and Smith, A. 2004. Diurnal changes in the transcriptome encoding enzymes of starch metabolism provide evidence for both transcriptional and posttranscriptional regulation of starch metabolism in Arabidopsis leaves. Plant Physiol. 136:2687-2699.

Smith, A. M., Zeeman, S. C., and Smith, S. M. 2005. Starch degradation. Annu. Rev. Plant Biol. 56:73-97.

Storr, T., and Hall, J. L. 1992. The effect of infection by Erysiphe pisi DC on acid and alkaline invertase activities and aspects of starch biochemistry in leaves of Pisum sativum L. New Phytol. 121:535-543.

Sturm, A. 1999. Invertases. Primary structures, functions, and roles in plant development and sucrose partitioning. Plant Physiol. 121:1-8.

Sturm, A., and Chrispeels, M. J. 1990. cDNA cloning of carrot extracellular beta-fructosidase and its expression in response to wounding and bacterial infection. Plant Cell 2:1107-1119.

Sutton, P. N., Gilbert, M. J., Williams, L. E., and Hall, J. L. 2007. Powdery mildew infection of wheat leaves changes host solute transport and invertase activity. Physiol. Plant. 129:787-795.

Swarbrick, P. J., Schulze-Lefert, P., and Scholes, J. D. 2006. Metabolic consequences of susceptibility and resistance (race-specific and broadspectrum) in barley leaves challenged with powdery mildew. Plant Cell Environ. 29:1061-1076.

Tang, X., Rolfe, S. A., and Scholes, J. D. 1996. The effect of Albugo candida (white blister rust) on the photosynthetic and carbohydrate metabolism of leaves of Arabidopsis thaliana. Plant Cell Environ. 19:967975.

Tiessen, A., Hendriks, J. H. M., Stitt, M., Branscheid, A., Gibon, Y., Farré, E. M., and Geigenberger, P. 2002. Starch synthesis in potato tubers is regulated by post-translational redox modification of ADP-Glucose Pyrophosphorylase: A novel regulatory mechanism linking starch synthesis to the sucrose supply. Plant Cell 14:2191-2213.

Triboush, S. O., Danilenko, N. G., and Davydenko, O. G. 1998. A method 
for isolation of chloroplast DNA and mitochondrial DNA from sunflower. Plant Mol. Biol. Rep. 16:183-189.

Trouvelot, S., Varnier, A., Allègre, M., Mercier, L., Baillieul, F., Arnould,

C., Gianinazzi-Pearson, V., Klarzynski, O., Joubert, J., Pugin, A., and Daire, X. 2008. A beta-1,3 glucan sulfate induces resistance in grapevine against Plasmopara viticola through priming of defense responses, including HR-like cell death. Mol. Plant-Microbe Interact. 21:232-243.

Tusher, V. G., Tibshirani, R., and Chu, G. 2001. Significance analysis of microarrays applied to the ionizing radiation response. Proc. Natl. Acad. Sci. U.S.A. 98:5116-5121.

Valsesia, G., Gobbin, D., Patocchi, A., Vecchione, A., Pertot, I., and Gessler, C. 2005. Development of a high-throughput method for quantification of Plasmopara viticola DNA in grapevine leaves by means of quantitative real-time polymerase chain reaction. Phytopathology 95:672-678.

van Kooten, O., and Snel, J. F. H. 1990. The use of chlorophyll fluorescence nomenclature in plant stress physiology. Photosynth. Res. 25:147-150.

Voegele, R. T., Wirsel, S., Moll, U., Lechner, M., and Mendgen, K. 2006. Cloning and characterization of a novel invertase from the obligate biotroph Uromyces fabae and analysis of expression patterns of host and pathogen invertases in the course of infection. Mol. Plant-Microbe Interact. 19:625-634.

Wellburn, A. R., and Lichtenthaler, H. 1984. Formulae and program to determine carotenoids and chlorophyll $\mathrm{a}$ and $\mathrm{b}$ of leaf extracts in different solvents. Pages 9-12 in: Advances in Photosynthesis Research, Vol. 2. C. Sybesma, ed. Martinus Njhorff/Dr. W. Junk Publishers, The Hague.

Wingler, A., Fritzius, T., Wiemken, A., Boller, T., and Aeschbacher, R. A.
2000. Trehalose induces the ADP-Glucose Pyrophosphorylase gene, ApL3, and starch synthesis in Arabidopsis. Plant Physiol. 124:105-114.

Wright, D. P., Baldwin, B. C., Shephard, M. C., and Scholes, J. D. 1995. Source-sink relationships in wheat leaves infected with powdery mildew. I. Alterations in carbohydrate metabolism. Physiol. Mol. Plant Pathol. 47:237-253.

Yu, T. S., Zeeman, S. C., Thorneycroft, D., Fulton, D. C., Dunstan, H., Lu, W. L., Hegemann, B., Tung, S. H., Umemoto, T., Chapple, A., Tsai, D. L., Wang, S. M., Smith, A. M., Chen, J., and Smith, S. M. 2005. Alphaamylase is not required for breakdown of transitory starch in Arabidopsis leaves. J. Biol. Chem. 280:9773-9779.

Zeeman, S. C., Smith, S. M., and Smith, A. M. 2007. The diurnal metabolism of leaf starch. Biochem. J. 401:13-28.

Zou, J., Rodriguez-Zas, S., Aldea, M., Li, M., Zhu, J., Gonzales, D. O., Vodkin, L. O., DeLucia, E., and Clough, S. J. 2005. Expression profiling soybean response to Pseudomonas syringae reveals new defenserelated genes and rapid HR-specific downregulation of photosynthesis. Mol. Plant-Microbe Interact. 18:1161-1174.

\section{AUTHOR-RECOMMENDED INTERNET RESOURCES}

Genoscope Grape Genome browser: www.genoscope.cns.fr/externe/GenomeBrowser/Vitis

Genoscope Vitis vinifera webpage: www.cns.fr/spip/Vitis-vinifera-e.html NimbleGen website : www.nimblegen.com/products/exp/custom.html\#vitus

NimbleGen user guide: www.nimblegen.com/products/lit/expression_userguide_v5p0.pdf 